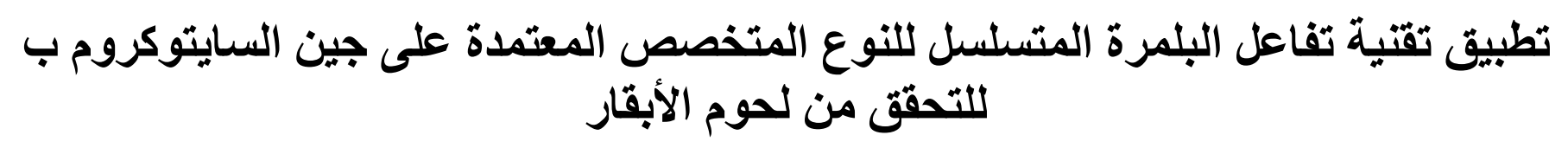

\author{
إسراء أحمد يونس و رعد عبد الغني السنجري \\ فرع الصحة العامة البيطرية، كلية الطب البيطري، جامعة الموصل، الموصل، العراق
}

أجريت هذه الدراسة على لحوم الأبقار المستوردة (الهندي و البرازيلي و الاسترالي) و وعينات من اللحوم المفرومة العائدة للأبقار

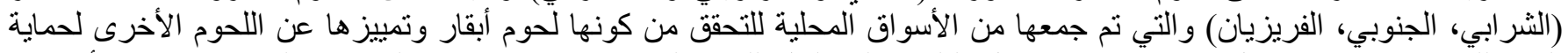

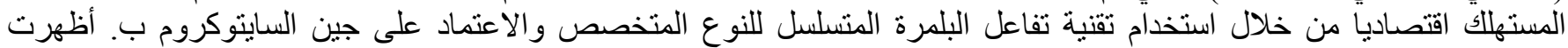

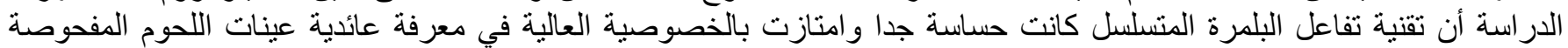

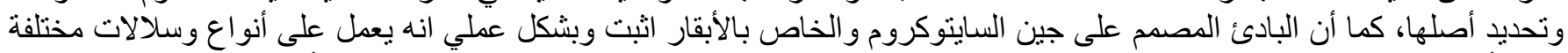

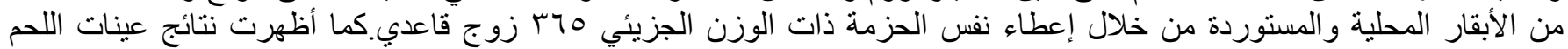

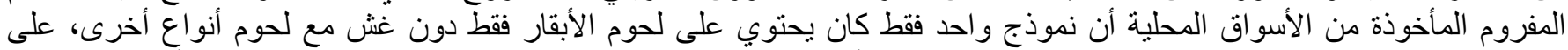

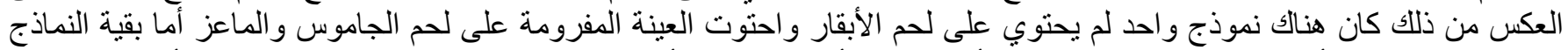

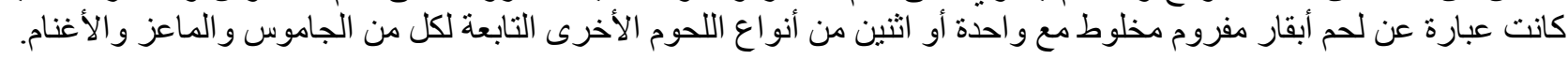

\title{
Application of species-specific polymerase chain reaction technique depending on cytochrome b gene for beef authentication
}

\author{
E.A. Younis and R.A. Al-Sanjary \\ Department of Veterinary Public Health, College of Veterinary Medicine, University of Mosul, Mosul, Iraq
}

\begin{abstract}
The study was conducted on imported beef meat (Indian, Brazilian and Australian), and spacement of minced beef meat (Al-jnobi, Al-sharabi) and Al-frezian collected from local grocery stores for beef authentication to differentiate them from others meats in order to protect consumer economically through applying Species-specific Polymerase Chain Reaction technique using n cytochrome $b$ gene. Results of this study indicated that Species-specific PCR technique was very sensitive and highly specific for the identification of the meat type, also it was found that the designed primer on mitochondrial cyt $b$ gene of beef proved practically proved to be applied on local and imported types of meat of different breeds, since gives the same molecular weight $365 \mathrm{bp}$ in all the same bands. From five minced beef samples, one sample was pure beef, other one contained no beef at all, while the remaining three samples were mixed meat of beef, buffalo, goat and mutton.
\end{abstract}

Available online at http://www.vetmedmosul.org/ijvs

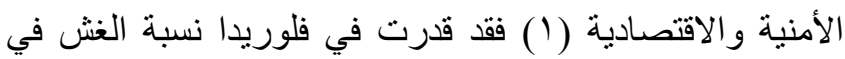

المقدمة

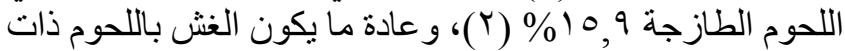

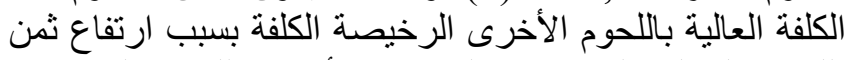

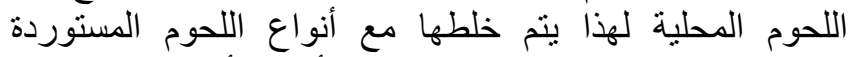

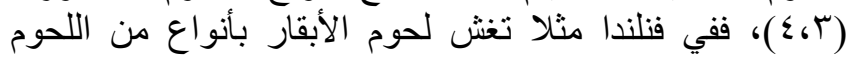

تو اجه معظم بلدان العالم سواء الدول الناميةً أو الدول المتقدمة

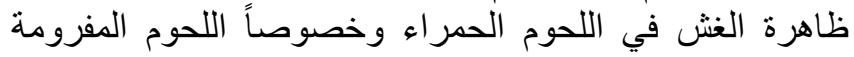

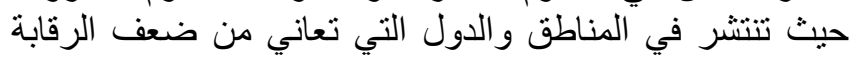


تقنية تفاعل البلمرة المتسلسل ومن ثم تحديد نوع الكائن الحي على الكي

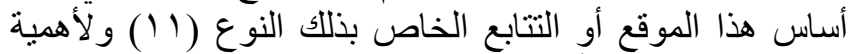

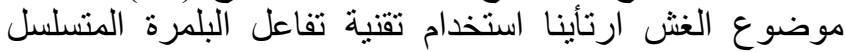

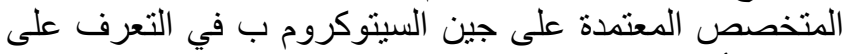

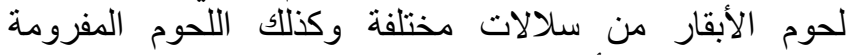
المعروضة في الأسواق المحلية والتحقق من عائديتها للحوم

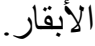

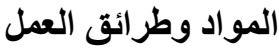

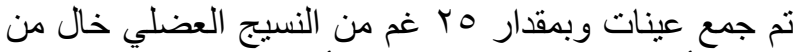

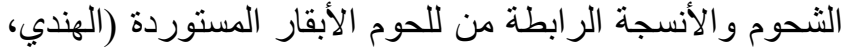

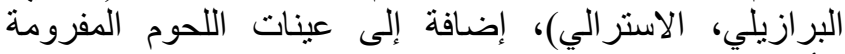

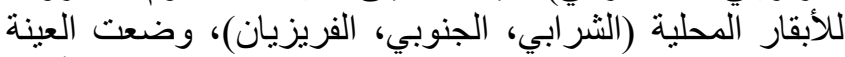

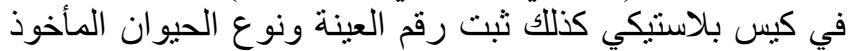

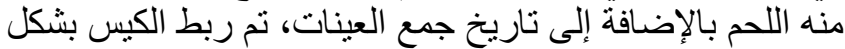

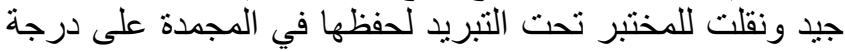

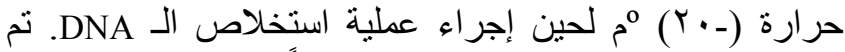

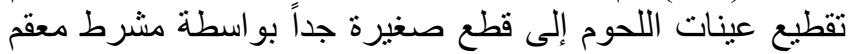

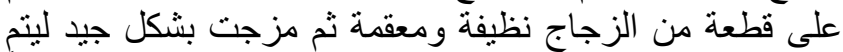

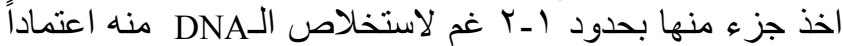

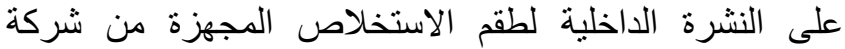
Sacace

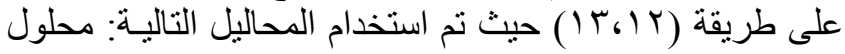

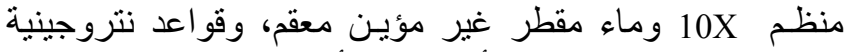

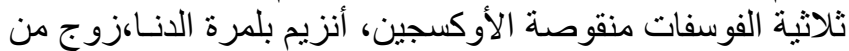

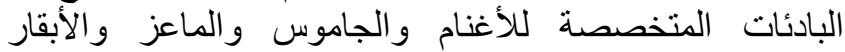

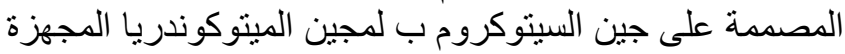
من شركة Germany promega وتتابع هذه البادئات هي كما يلي:
الأرخص ثمنا مثل لحوم الخنازير وكذللك في انكلترا و أمريكا

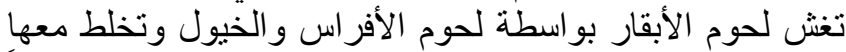

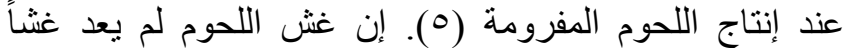

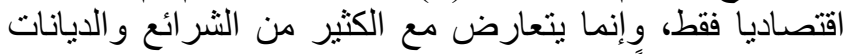

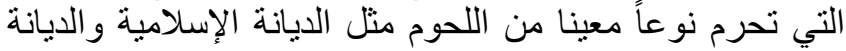

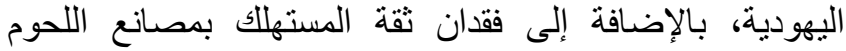

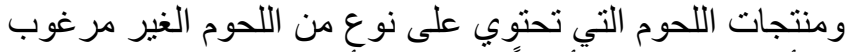

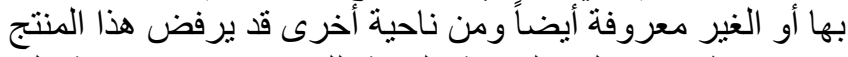

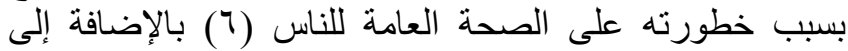

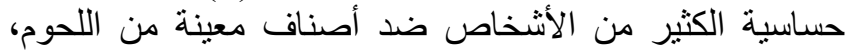

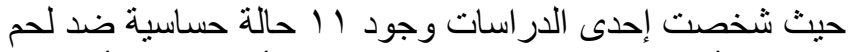

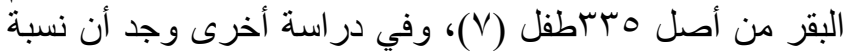

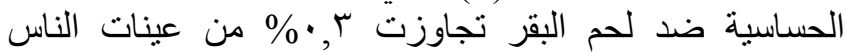

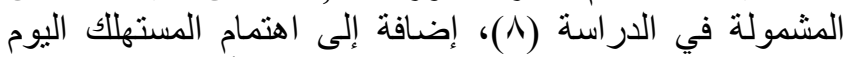

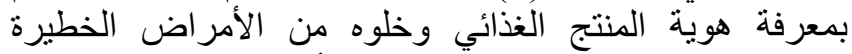

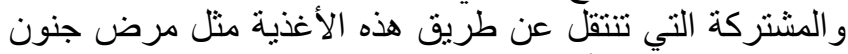

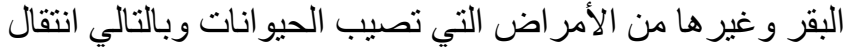

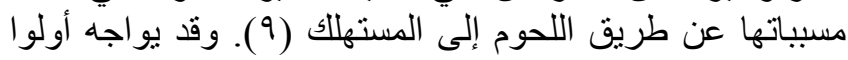

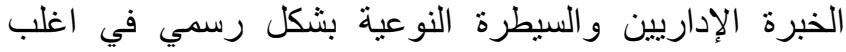

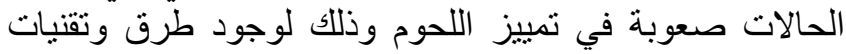

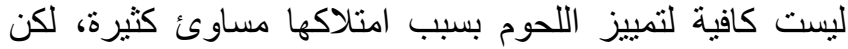

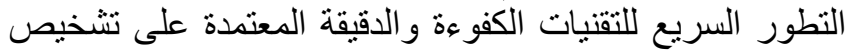

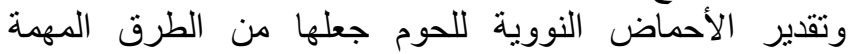

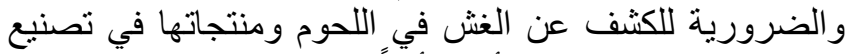
المنتجات الغذائية لتكون أكثر أمناً في المجتمع وللحفاظ على اللى

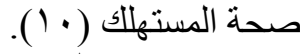

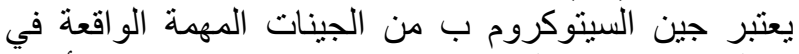

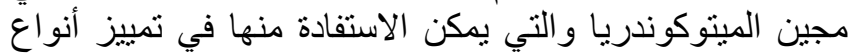

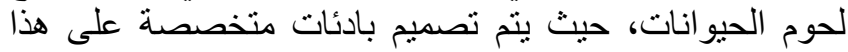
الجين و الذي بسمح بحصول تضاعف لملايين المرات من خلال

\begin{tabular}{|c|c|c|}
\hline \multirow{2}{*}{$\begin{array}{r}\text { ATT AGT CAA TGT ATA TTC TGA ATC TTA GG GAG GTT } \\
\text { ATT TTC GAT AGT GCT AGC TAC }\end{array}$} & رقم البادئ F/R & Mt-cyt b اسم البادئ \\
\hline & الأول & الأغنام \\
\hline $\begin{array}{r}\text { ACA CGT AGG ACG CAT ATA C } \\
\text { CCA TTC AGG CTT GAT GTG G }\end{array}$ & 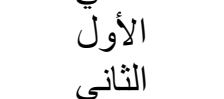 & الجاموس \\
\hline $\begin{array}{l}\text { CAT ACA TAT CGG ACG AGG TC } \\
\text { GTA ATA TTA GAA CAA GAA TTA GTA GC }\end{array}$ & 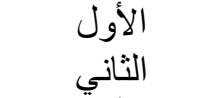 & الماعز \\
\hline $\begin{array}{l}\text { GCC AAT TGC TAT GAT GAT AAA TGG A } \\
\text { GGC TTA TAT TAC GGG TCT TAC ACT }\end{array}$ & 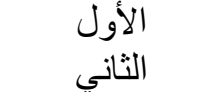 & الأبقار \\
\hline
\end{tabular}

VY و م o or

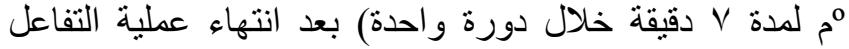

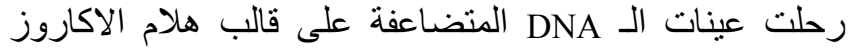

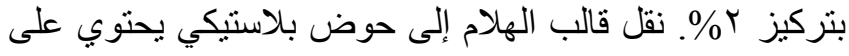

وضعت الأنابيب الحاوية على المواد المذكورة أعلاه في

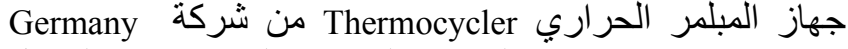

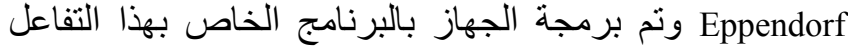

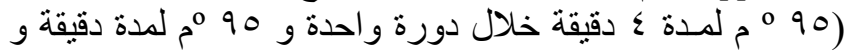




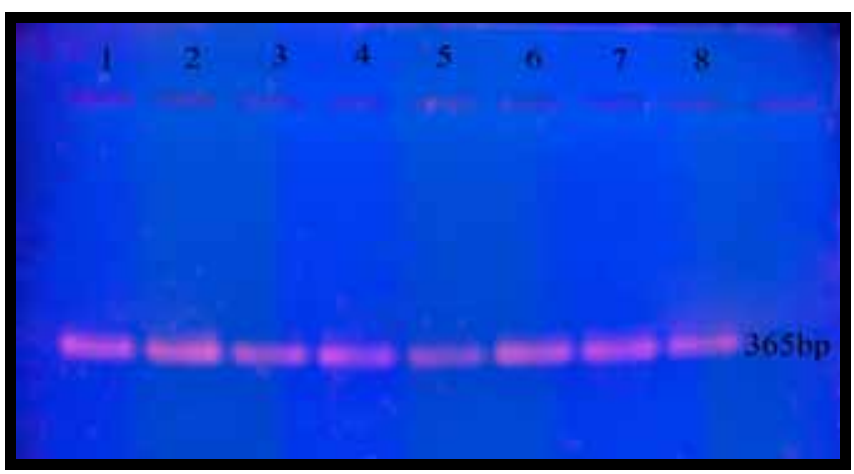

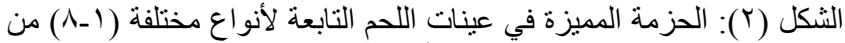

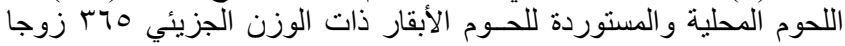

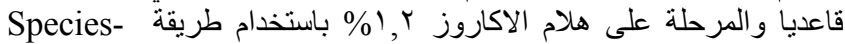
specific PCR

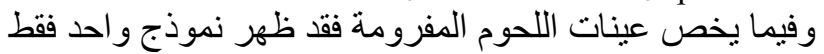

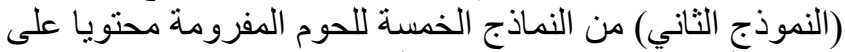

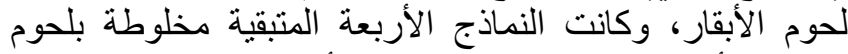

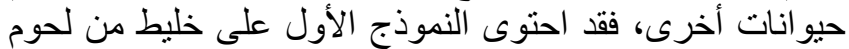

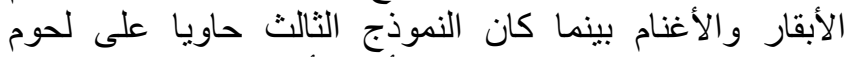

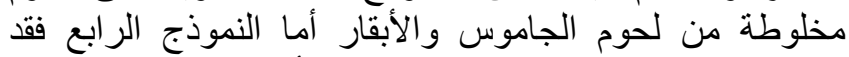

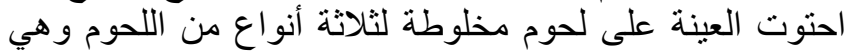

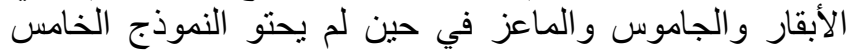

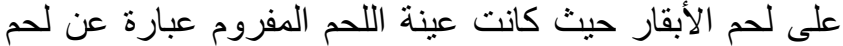
مخلوط من لحم الجاموس والماعز (الجدول ( ).

الجدول (1) حزم DNA المتضلاعف في عينات اللحوم المفرومة و التي تظهر في بعض منها وجود أكثر من نوع من اللحم.

\begin{tabular}{|c|c|c|c|c|c|}
\hline أغنام & أبقار & ماعز & جاموس & المفترض & اللحوم المفرومة \\
\hline+ & + & - & - & أبقار & نموذج لحم رقم 1 \\
\hline- & + & - & - & أبقار & نموذج لحم رقم r \\
\hline- & + & - & + & أبقار & نموذج لحم رقم \\
\hline- & + & + & + & أبقار & نموذج لحم رقم ع \\
\hline- & - & + & + & أبقار & نموذج لحم رقم 0 \\
\hline
\end{tabular}

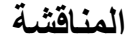

يعد التعرف على نوع اللحوم وتحديد أصل ومعرفة عائديتها

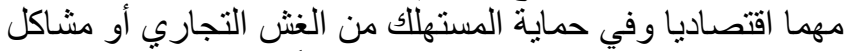

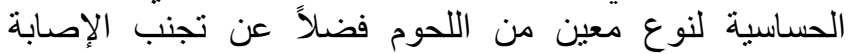

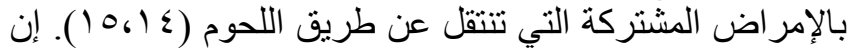

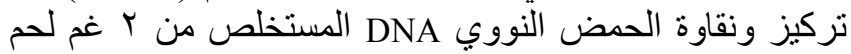
في هذه الدراسة كانت كافية لاختبار ات الغش بتقنية تفاعل البلمرة
صبغة الأثيديوم برومايد لمدة ساعة واحدة بعدها يصور الهلام

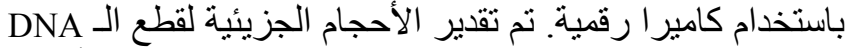

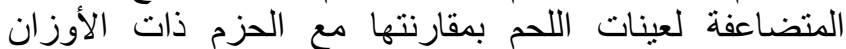

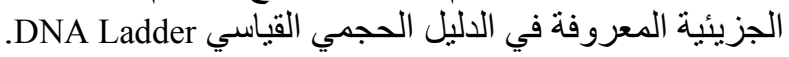

النتائج

أظهرت الدراسة أن تركيز الحمض النووي (DNA)

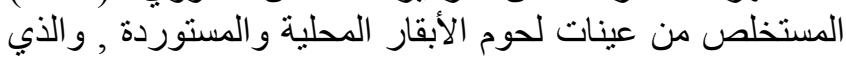

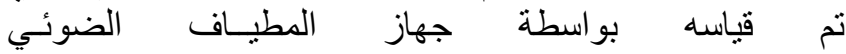

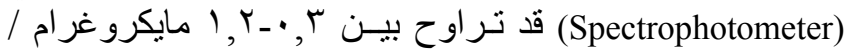

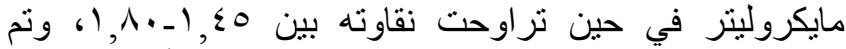

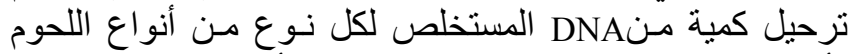

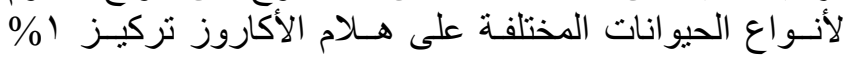

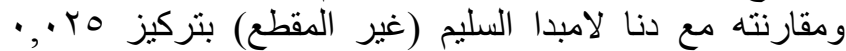
مايكرو غر ام / مايكروليتر وذللك للتأكد من عملية الاستخلاص للا لإيز

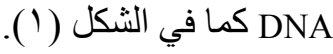

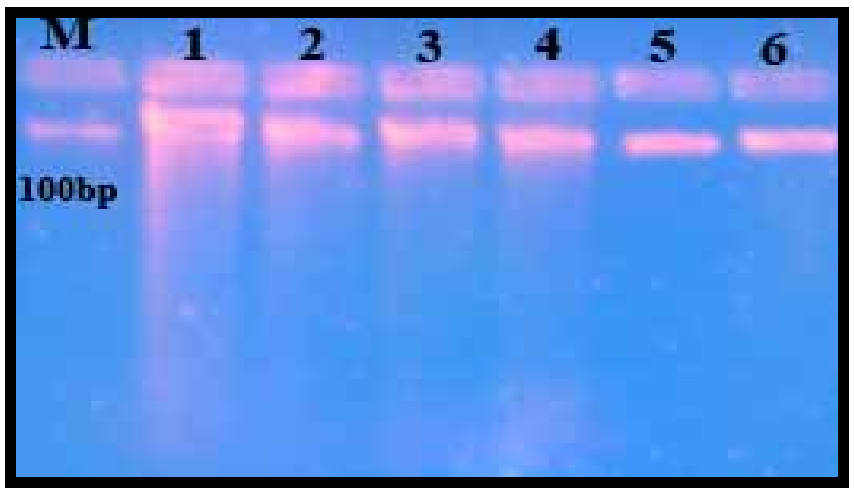

الشكل (1) استخلاص DNA من عينـات اللحم المتمنلة بالأرقام (1) (1) أبقار

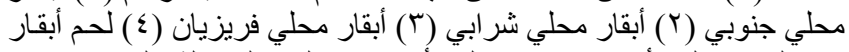

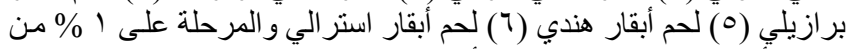
هلام الأكاروز ويمثل (M) ألدليل ألحجمي القياسي ألمتكون من دنا لامبدا غير الحير

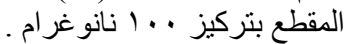
كما أظهرت النتائج حزمة وامثة واحدة فقط لجميع لعينات لحوم

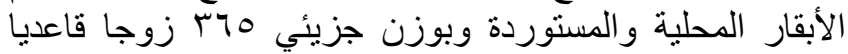

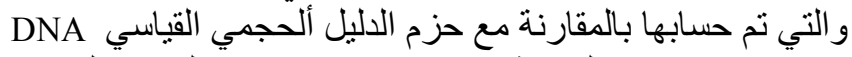
Ladder

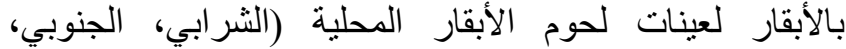

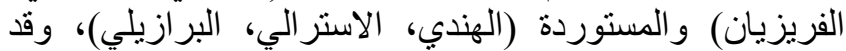

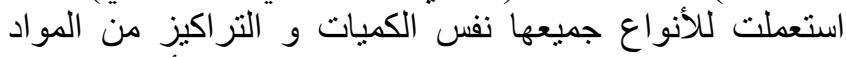

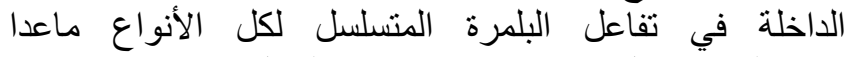

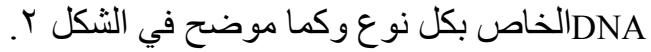




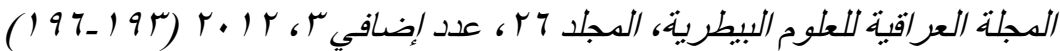

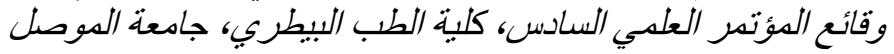

2. Hsich HM, Chiang HL, Tsai LC, Lai SY, Huang NE, Linacre A, Lee JCI. Cytochrome $b$ gene for species identification of the conservation animals. Forensic Sci Int. 2001; 122: 7-18.

3. Rao KBA, Kowale B, Nand Totey SM. Sex-Specific identification of raw meat from cattle, buffalo, sheep and goat. Meat Science $1995 ; 39$ : 123-126.

4. USDA- FSIS. Nutrition Labelig:Nutrient content claims on multiscrve, meat-type meat and poultry. Poultry Products. Available Form USDA- FSIS, 2003. http:www.fssis.usda.gov/ oppde / rdad /00 - 046p. htm. posted 050304 .

5. King NL, Kurth I. Analysis of raw beef samples for adulteranat meat species by enzyme- staining of isoelectric focusing gel. J Food Sci. 1984; 47: 1608-1612.

6. Sherikar AT, Khot JB, Jayarao BM, pillai SR. Use of species- specific antisera to adrenal heat - stable antigens for the identification of raw and cooked meats by agar gel diffusion and counter immunoelectrophoretic techniques. J Sci Food Agri. 1988 ; 44: 63-73.

7. Werfel SJ, Cooke SK, Sampson H A. Clinical Reactivity to beef in children allergic to cows milk. J Allergy Clin Immunology 1997 ;3: 293-300.

8. Fiocchi A, Restani P, Riva E. Beef allergy in children nutrition. International J App Basic Nutrional Sci. 2000 ; 16: 454-457.

9. Brodmann p. Development and Validation of species identification, ph.D. Thesis. University of Basel 2002.

10. Mane BG. Identification of species origin of meat by random amplified polymorphic DNA - polymerase chain reaction (RAPDPCR). M. V. SC. Thesis submitted to G.B.P.U.A. and T., Pantnagar, 2004.

11. Kocher TD , Thomas WK, Meyer A, Edwards SV, Paabo S , Villablanca FX, Wilson AC. Dynamics of mitochondrial DNA evolution in animals: amplification and sequencing with conserved primers. Proc Natl Acad Sci USA. 1989 ; 86: 6196-6200.

12. Bottero MT , Civera T, Anastasio A, Turi RM , Rosati S.Identification of cow 's milk in " buffalo" cheese by duplex polymerase chain reaction. J Food Prot. 2002 ; 65(2): 362-366.

13. Meyer R, Hofelein C, Luthy J, Candrian V. Polymerase chain reaction restriction fragment length polymorphism analysis:a sample method for species identification in food. J AOAC Int. 1995 ; 76(6): 15421551 .

14. Abdel-Rahman SM,El-saadani MA, Ashry KM, Haggag AS.Detection of adulteration and identification of Catś ,Dogś, Donkys and Horses meat using species-specific PCR and PCR-RFLP Techniques. Aust. J. Basic Appl Sci. 2009 ; 3(3):1716-1719.

15. Ong SB, Zuraini MI, Jurin WG, Cheah YK, Tunung R, Chai C,Haryani Y, Ghazali FM , Son R. Meat molecular detection: Sensitivity of polymerase chain reaction-Restriction Fragment Length Polymorphism in species differentiation of meat from animal origin. ASEAN Food J. 2007 ; 14(1): 51-59.

16. Ahmed MMM , Abdel-Rahman SM , El-Hanafy AA. Application of Species - specific polymerase chain reaction (PCR) and cytocrome b gene for different meat species authentication. Biotechnol. 2007 ; 6(3): 426-430.

17. Jain S, Brahmbhait MN, Rank DN, Joshi CG, Solank JV.Use of cytochrome $\mathrm{b}$ gene variability in detecting meat species by multiplex PCR assay. Indian J Anim Sci. 2007 ; 77(9): 880-881.

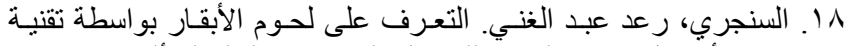

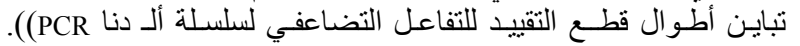

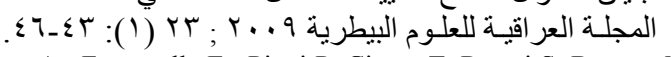

19. Dalmasso A, Fontanella E, Piatti P, Civera T, Rosati S, Bottero MT. A multiplex PCR assay for identification of animal species in feedstuffs. Molecular and Cellular Probes 2004 ; 18: 81-87.

20. Jha VK, Kumar AM, Okhot UV. Indirect Enzyme Linked Immuno sorbent Assay in detection and differentiation of cooked and raw pork from meats of other species. J Food Sci Technol. 2003 ; 40: 254-256.
المتسلسل، و استخدم (7 ( ) ه, • غم من النسيج في استخلاص

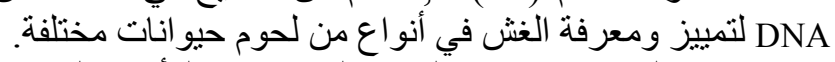
في هذه الدراسة استخدم البادئ المتخصص لئ للأبقار المصنم

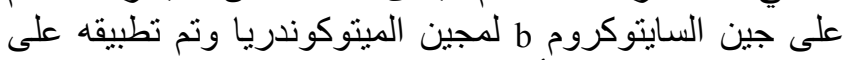

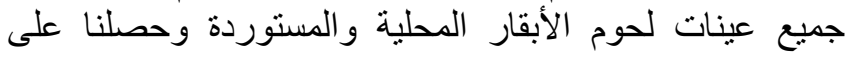

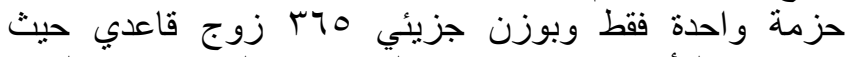

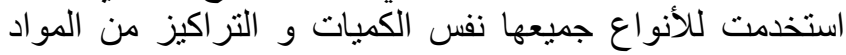

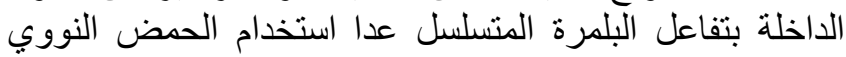

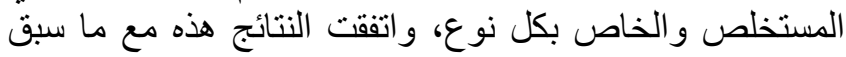

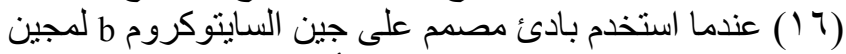

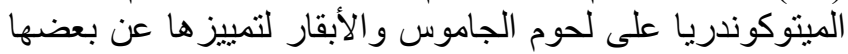

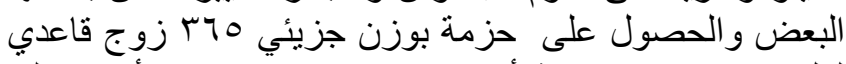
لكل منهما، وفي دراسة أخرى استخدم بادئ مصدم أيضنا على جلى

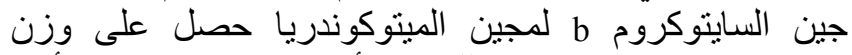
جزيئي جV

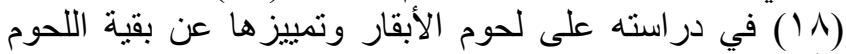

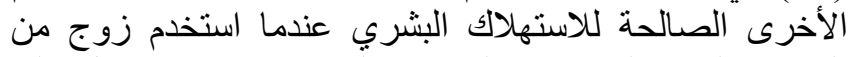

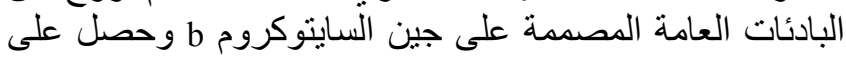

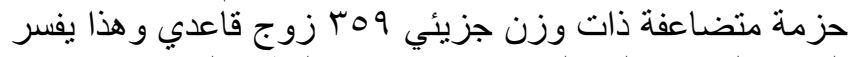

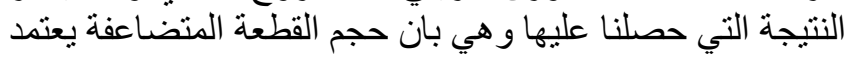

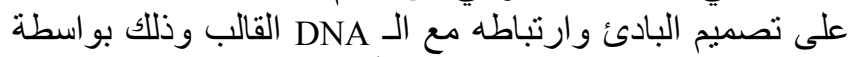

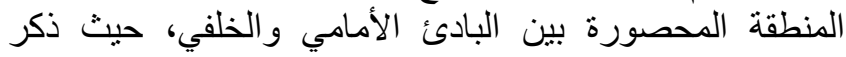
Dalmasoo تختلف في قيمة أوزانها الجزيئية وذلك حسب تصبي تصيم البادئ و الذي بعتمد على نوع الجين الذي في يصمح عليه البادئ. إن فقدان ثقة المستهلك بمصانع اللحوم ومنتجاتها التي تحتوي

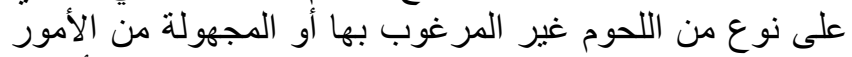
المهمة التي تواجه العاملين في مجال صناعة اللحوم لأسباب عديدة تخص المستهلك من الناحية الصحية و الدينية و الاقتصادية الصاية (Y. (Y)، ففي هذه الدراسة ومن خلال إجراء تقنية تفاعل البلمرة

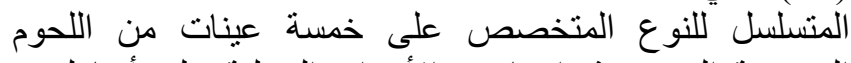
المفرومة التي تم شراءها من الأسواق المحلية على المه أنها لحوم

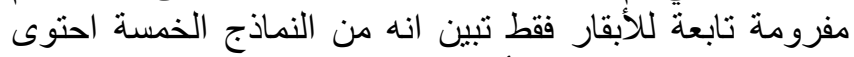

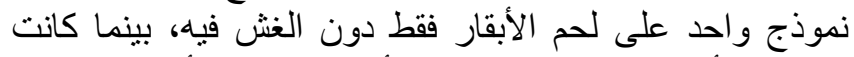

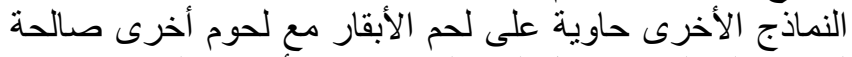

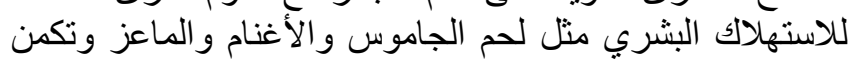

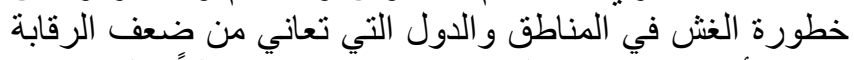

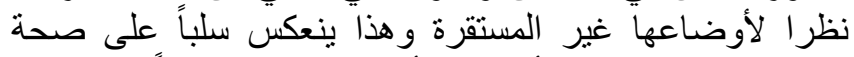
المستهلكين وحقوقهم الأساسية وأكثر الحالات خطراً هي السلع المستوردة منتهية الصدلاحية ( ( ). المصادر

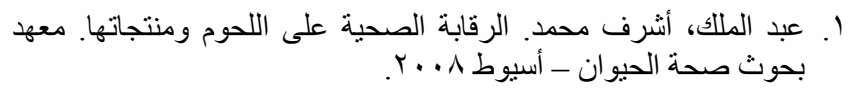

